Fecha de recepción: marzo 2021 Fecha de aceptación: abril 2021 Versión final: mayo 2021

\section{Argumentación, polémica y emociones en Alberto Fernández ante el COVID-19}

María Alejandra Vitale ${ }^{(1)}$

Resumen: En un trabajo previo (Vitale, 2020) analicé la construcción de una imagen de sí o ethos pedagógico oral en el discurso monologal del presidente argentino Alberto Fernández referido a la pandemia COVID-19, en las conferencias de prensa y anuncios oficiales que pronunció entre el 15 de marzo y el 17 julio de 2020. En este artículo, me centro en sus discursos producidos entre el 31 de julio de 2020 y el 12 de octubre de 2020 y doy cuenta de cómo se mantiene ese ethos a la vez que caracterizo la mayor presencia de técnicas argumentativas (Perelman y Olbrechts-Tyteca, 1989), dimensión polémica (Amossy, 2014) y pathos (Plantin, 2010, 2011) en relación con la primera etapa de su comunicación política sobre la pandemia. Considero, asimismo, la puesta en escena mediática (Cingolani y Fernández, 2010, 2019; Verón, 2001) para describir las reformulaciones de esa comunicación, signada en esta segunda etapa por el aumento de contagios y muertos por COVID-19, la propagación del virus por toda la Argentina y el incremento en el enfrentamiento entre el gobierno nacional y la oposición, incluido el jefe de gobierno de la Ciudad de Buenos Aires.

Palabras clave: argumentación - COVID-19 - polémica - emociones - escena mediática.

[Resúmenes en inglés y portugués en las páginas 89-90]

(1) María Alejandra Vitale. Doctora en Lingüística por la Universidad de Buenos Aires, donde se desempeña como Profesora Titular de Semiología (CBC) e investigadora del Instituto de Lingüística (FFyL). Obtubo el Posdoctorado en Estudios Lingüísticos en la Universidad Federal de Minas Gerais, Brasil. Ha sido presidente de la Asociación Argentina de Retórica, de la Asociación Latinoamericana de Retórica y actualmente preside la Organización Iberoamericana de Retórica. Sus líneas de investigación son el análisis del discurso político y de los servicios de inteligencia. Dirige proyectos UBACyT y PICT. Es líder del Grupo de Investigación en archivos de la represión (GIAR): https://grupoinvestigacionarchivosdelarepresion.wordpress.com. Entre sus últimos libros, se ubican ¿Cómo pudo suceder? Prensa escrita y golpismo en Argentina (1930-1976), Vigilar la sociedad. Estudios discursivos sobre inteligencia policial bonaerense y Rutinas del mal. Estudios discursivos sobre archivos de la represión. alejandravitale@filo.uba. 


\section{Introducción}

La pandemia COVID-19 constituye un acontecimiento histórico y semiodiscursivo inédito, que ya ha motivado variadas publicaciones académicas que lo abordan desde los estudios del discurso y la semiótica (Karam Cárdenas, 2020; Fabbri y Ormaneze, 2020; Fausto Neto, 2020; Han, 2020; Lebaud, 2020; MIRCo, 2020; Slimovich, 2021). Por mi parte, en un trabajo previo (Vitale, 2020) analicé la construcción de una imagen de sí o ethos pedagógico oral en el discurso monologal del presidente argentino Alberto Fernández referido a la pandemia COVID-19, en las conferencias de prensa y anuncios oficiales que pronunció entre el 15 de marzo y el 17 julio de 2020. En este artículo, parto de la pregunta de cómo han incidido en la discursividad posterior de Fernández sobre el COVID-19 las mutaciones de las condiciones de producción. Me centro así en sus discursos producidos entre el 31 de julio y el 12 de octubre de 2020 y describo cómo se mantiene ese ethos previo a la vez que caracterizo la mayor presencia de técnicas argumentativas, dimensión polémica y pathos - o construcción de las emociones en el discurso- en relación con la primera etapa de su comunicación política sobre la pandemia. Considero, asimismo, la puesta en escena mediática (Cingolani y Fernández, 2010, 2019; Verón, 2001) para analizar las reformulaciones de esa comunicación, signada en esta segunda etapa por el aumento de contagios y muertes por COVID-19, la propagación del virus por toda la Argentina y el incremento en el enfrentamiento entre el gobierno nacional y la oposición, incluido el jefe de gobierno de la Ciudad de Buenos Aires.

\section{Consideraciones metodológicas}

El corpus fue seleccionado sobre la base de dos criterios, temático y cronológico. De la discursividad de Fernández, seleccioné aquella dedicada al COVID-19 y producida, dije, entre el 31 de julio y el 12 de octubre de 2020. ${ }^{1}$ La metodología es cualitativa (Vasilachis de Gialdino, 2006), por lo que prioriza el interés por el significado y la interpretación, pone el énfasis en la importancia del contexto y de los procesos e implementa una estrategia inductiva y hermenéutica.

El marco general es el análisis del discurso como campo interdisciplinario (Maingueneau, 2014), de allí que integro una perspectiva retórico-discursiva que articula el estudio del ethos formulado por Maingueneau (2002), con las propuestas de Perelman y OlbrechtsTyteca (1989) sobre las técnicas argumentativas, las de Amossy (2014) sobre la polémica y las de Plantin $(2010,2011)$ sobre el pathos. Combino esta perspectiva retórico-discursiva con los aportes de Verón $(1983,1987,2001)$ sobre el discurso político y la semiosis de la puesta en escena mediática.

En relación al ethos, recupero las características del discurso pedagógico oral descriptas por Molina (2003); en lo relativo a las técnicas argumentativas, priorizo desde Perelman y Olbrechts-Tyteca (1989) los argumentos de más peso en el corpus en términos persuasivos (la analogía, el de autoridad y el de la dirección). En cuanto a la dimensión polémica, focalizo las negaciones (García Negroni, 1998; Maingueneau, 1987) y para el estudio de 
las emociones me detengo, desde Plantin $(2010,2011)$, en la distinción entre emoción dicha y mostrada, emoción autoatribuida o heteroatribuida, emoción eufórica y disfórica y la noción de tópico para generar emoción. Entre los aportes de Verón (1987) sobre el discurso político, contemplo aspectos ligados a los tipos de destinatarios y las entidades que los refieren.

En la semiosis de la puesta en escena mediática incluyo la ubicación en el espacio del cuerpo presidencial (Verón, 2001), en particular entre quiénes se sienta, y los decorados y objetos que lo acompañan; para dar cuenta de cómo producen sentidos, utilizo la noción de connotación (Barthes, 1992). Por otra parte, incorporo el régimen de la mirada (Verón, 1983) y la intericonicidad (Courtine, 2011).

\section{El ethos pedagógico oral}

Los discursos de Alberto Fernández producidos entre el 31 de julio y el 12 de octubre de 2020 mantienen la construcción del ethos pedagógico oral que se identifica en sus alocuciones previas sobre el COVID-19 (Vitale, 2020), lo que tiende a dotarlo de una identidad pública coherente. En efecto, continúan presentes las siguientes características del discurso pedagógico oral consideradas por Molina (2003):

- Habla metacomunicativa: se trata de un discurso que se refiere al propio proceso de enseñanza-aprendizaje y a la comprensión por parte de los alumnos. Fernández, por ejemplo, afirma sobre su propia alocución: "acá estamos entendiendo" (14/08/2020) o "Todo esto yo lo recuerdo y lo planteo para que entendamos" (14/08/2020). Al verbo "entender" (31/07/2020, se suma el uso de otros verbos de entendimiento, que expresan operaciones mentales, como "analizar" (03/08/2020), "hacer una reflexión" (31/07/2020), "explicar" (13/08/2020) y “darse cuenta” (12/10/2020).

- Explicaciones: se manifiestan en preguntas didácticas que expresan el punto de vista del alumno y que son respondidas por el profesor. Fernández, por ejemplo, pregunta “¿cómo es posible que con semejante inclemencia de tiempo se hayan generado semejante cantidad de contagios?" y él mismo responde "La explicación es una sola: los encuentros sociales" (06/08/2020). Asimismo, se expresan en paráfrasis intradiscursivas que aclaran el significado de un término y presentan dos segmentos textuales como equivalentes semánticos (Zamudio y Atorresi 2000), por ejemplo cuando el presidente argentino sostiene: "la tasa de letalidad, es decir qué porcentaje de infectados que ha fallecido como consecuencia del coronavirus" (12/10/2020). ${ }^{3}$

- Recapitulaciones de los contenidos dictados en otras clases y reformulaciones del desarrollo de la propia clase. Alberto Fernández, por ejemplo, sostiene: "Yo les dije al comienzo, todavía en el total del país tenemos 55 por ciento de camas ocupadas, y 45 por ciento de camas disponibles" (06/08/2020) y "Yo los invito a que repasemos juntos esos datos, porque me van a permitir explicar en qué situación estamos" (12/10/2020). ${ }^{4}$

- Recontextualización: el profesor tiene más poder que el alumno al recontextualizar (Bernstein, 2005) el discurso especializado o científico ante quienes lo desconocen. De 
esta manera, son protagonistas en las alocuciones de Alberto Fernández las cifras y los porcentajes elaborados por expertos en epidemiología y estadísticas: "el 88 por ciento de las camas de Terapia Intensiva están siendo utilizadas, hoy, en Río Negro; el 81 por ciento en Mendoza; el 80 por ciento en Tucumán (..)" (29/09/2020).5

- Uso de recursos didácticos: el presidente argentino exhibe gráficos de líneas y de tablas o mapas, que muestran los datos recontextualizados en su discurso pedagógico oral y ejemplificados arriba. En este sentido, el discurso verbal que acompaña la exhibición de estos recursos didácticos funciona en términos de R. Barthes (1992) como un anclaje, porque orienta ante el auditorio la lectura de las imágenes que muestra y ancla su sentido con miras a una correcta interpretación.

Como ya he planteado (Vitale, 2020), el ethos pedagógico oral de Alberto Fernández tiende a legitimar su política pública en torno al COVID-19, dotándolo de una autoridad basada en su saber y en el de ser el intermediario entre un discurso experto y el auditorio. Fernández busca persuadir a su audiencia de la eficacia de su política sanitaria a la vez de que acate el denominado "Aislamiento Social, Preventivo y Obligatorio" (ASPO), que se extendió hasta el 6 de noviembre de 2020.

El ethos pedagógico oral, por otra parte, atenúa la polémica propia del discurso político (Verón, 1987), puesto que el educador, como señalan Perelman y Olbrechts-Tyteca (1989), trata sobre asuntos que no son para el auditorio objeto de controversias. El educador, agregan, enuncia verdades o defiende valores que no generan oposiciones y funciona como portavoz de una comunidad, en el caso del ethos pedagógico oral de Alberto Fernández, la comunidad científica.

Sin embargo, adelanté que si se comparan los discursos del presidente argentino pronunciados entre el 31 de julio y el 12 de octubre de 2020 sobre el COVID-19 con los que emitió entre el 15 de marzo y el 17 julio de 2020, se observa que en esta segunda etapa hay un mayor uso de recursos argumentativos, específicamente tipos de argumentos y apelación a las emociones. La dimensión polémica, asimismo, está más presente. Se infiere así que el desacuerdo sobre la política sanitaria implementada por Alberto Fernández era mayor, lo que se confirma considerando las condiciones de producción. En efecto, el ex presidente Mauricio Macri, en especial a partir del 8 de julio de 2020, acrecentó su oposición pública al ASPO al tiempo que apoyó o promovió protestas que sectores opositores desarrollaron contra la política sanitaria de Alberto Fernández. Por otra parte, como el mismo Fernández informa en sus alocuciones con cifras y porcentajes precisos, el número de contagios y la ocupación de camas en los hospitales por el COVID-19 fue aumentando, al tiempo que se acrecentaron las muertes y el virus se expandió desde el llamado AMBA, Aérea Metropolitana de Buenos Aires, que incluye la Ciudad de Buenos Aires y la Provincia de Buenos Aires, hacia toda la Argentina. La imagen pública positiva de Alberto Fernández, a su vez, fue bajando desde el inicio de la pandemia y la implementación del ASPO, según las encuestas. ${ }^{6}$ El gobierno, por su parte, quitó un punto del porcentaje de coparticipación federal a la Ciudad de Buenos Aires en el contexto de la necesidad de aumentar el salario de la policía bonaerense, lo que resquebrajó la relación con el Jefe de la Ciudad de Buenos Aires, Horacio Rodríguez Larreta, de la oposición, y con quien hasta el momento la relación había sido muy cordial. ${ }^{?}$ 


\section{Las técnicas argumentativas}

Entre las técnicas argumentativas usadas por Alberto Fernández en los discursos aquí analizados se destacan por su riqueza en términos persuasivos tres tipos de argumentos: la analogía, el argumento de autoridad y el argumento de la dirección.

\section{La analogía}

Este tipo de argumento ${ }^{8}$ es central en el discurso del 13 de agosto de 2020 y busca hacer aceptable ante el auditorio una cruda verdad -hay más contagios, más muertos, más camas ocupadas y el virus se expandió- a la vez que mitigar el posible efecto adverso en el auditorio respecto de la política sanitaria implementada por su gobierno hasta el momento. Es decir, que esas malas noticias sean recibidas lo más favorablemente posible y, como veremos, sin intranquilizar demasiado.

En ese discurso, hay tres analogías vinculadas con el campo de la medicina que ubican a Fernández en el lugar de un médico. La primera analogía afirma:

Frente a un enfermo que está ante una situación complicada, ¿el médico debe decirle la verdad y participarlo de la complicación en la que está el enfermo, o no, debe retacearle esa información para que en todo caso padezca menos, para que en todo caso psicológicamente lo lleve mejor? (...) Yo creo que los médicos deben contarnos la verdad cuando estamos enfermos, y deben decirnos los problemas que tenemos que enfrentar por esa enfermedad, y deben ayudarnos a sobrellevar esa enfermedad si esa enfermedad es crónica, y si inclusive esa enfermedad es terminal. Lo que no puede hacer es darnos placebos, porque los placebos nos hacen creer que estamos mejorando y en verdad no lo estamos, y lo que necesitamos es encontrar una solución a nuestra enfermedad. Digo esto porque el mundo está enfermo, el mundo está enfermo. Y la verdad que la única medicina, que hemos encontrado hasta aquí, es acotar lo máximo posible la circulación de las personas y el encuentro de las personas, la cercanía. Y, por lo tanto, yo hago de la verdad un culto, y no me gusta decir una cosa por otra.

Esta analogía establece la similitud entre un médico, que debe decirle la verdad a un paciente enfermo aun cuando pueda intranquilizarlo, y Alberto Fernández, que debe decirle la verdad a su auditorio, aunque le provoque intranquilidad. Como sostienen Perelman y Olbrechts-Tyteca (1989), la analogía genera una interacción entre los elementos del tema (que contienen el objeto del discurso y la conclusión) y del foro (que sirven para sostener el razonamiento), sobre todo una transferencia de valor entre el foro y el tema. De esta manera, los valores positivos estereotipados que rodean al médico (foro), sanar y cuidar, recaen en Alberto Fernández, lo que tiende a hacer aceptables sus verdades negativas en torno al COVID-19. Esta analogía tiende a fortalecer su imagen pública y su liderazgo, asimismo, porque da pie a un ethos dicho en el que se autorrepresenta como alguien que 
siempre dice la verdad, un valor también en el campo político, normalmente asociado de modo estereotipado con la mentira. Por último, la analogía tiende a generar o acrecentar la adhesión en torno a la política sanitaria de Fernández, el ASPO, dado que queda en el lugar del "remedio" para la enfermedad.

Las otras dos analogías tienen una función refutativa frente a quienes se oponen al ASPO y lo asocian con una posición autoritaria que coarta las libertades, lo que da cuenta de la dimensión polémica presente en los discursos analizados:

es lo mismo como si un médico me dijera "no le ponga más sal a su comida porque tiene la presión alta”, y yo le dijera "está restringiendo mi libertad de comer sal". Es exactamente lo mismo. En verdad acá no hay libertades en juego, lo que hay es lo que nos pasa cuando enfrentamos una enfermedad y el mundo está enfermo, tenemos que tener ciertas restricciones para tener cuidado, simplemente.

De modo consistente con la primera analogía, en esta también el presidente argentino se ubica en el lugar del médico y nuevamente el ASPO queda asociado a un remedio para la salud, en este caso la prohibición de la sal que el médico hace al enfermo. En la tercera analogía se repite la misma estrategia:

Seguramente si tenemos problemas aeróbicos nos dirán tratá de no correr, tratá de no excitarte, y con eso no me están quitando libertades, me están cuidando. Y seguramente si tengo diabetes me dirán tratá de no comer dulces, de no comer harinas, y con eso no me están quitando libertades, me están cuidando.

En los enunciados citados, el ASPO queda equiparado al "no correr", "no excitarse", "no comer dulces", "no comer harinas", como medios para sanar a un enfermo o mantenerlo saludable. El carácter refutativo de estas dos últimas analogías queda marcado en las negaciones metalingüísticas (García Negroni, 1998) "no hay libertades en juego", "no me están quitando libertades", en las que los enunciados afirmativos rechazados fueron proferidos por la oposición al gobierno de Alberto Fernández.

\section{El argumento de autoridad}

Este argumento utiliza, aclaran Perelman y Olbrechts-Tyteca (1989), actos o juicios de una persona o de un grupo de personas como medio de prueba en favor de una tesis. El tipo de autoridad invocada, agrego por mi parte, permite caracterizar al orador y a su propio auditorio en cuanto es su construcción, puesto que exhibe sus competencias culturales o ideológicas a la vez que sobreentiende que esa autoridad invocada es aceptada por el auditorio.

En este sentido, Alberto Fernández se apoya en un enunciado formulado por el Dr. Pedro Cahn, reconocido infectólogo de la Fundación Huésped y miembro del Comité de Expertos que lo asesora. Este enunciado es reformulado en sus diversos discursos, desde los 
primeros sobre el COVID-19, de modo que le otorga coherencia a la vez que manifiesta la importancia que Fernández le da al saber experto del campo médico: "Como muchas veces he repetido, siguiendo una enseñanza del doctor Cahn, en verdad el virus no nos busca, nosotros vamos a buscarlo (31/07/2020), "como siempre dice el doctor Cahn: "el virus no nos busca, sino que nosotros vamos a buscarlo" (14/08/2020), "como siempre recuerdo una frase, que me ha dicho el Doctor Pedro Cahn, el virus está y nosotros vamos a buscarlo y vamos a buscarlo con esa circulación" (29/09/2020).

Este argumento de autoridad apoya el ASPO para evitar que se propague el COVID-19. En otras dos oportunidades, Alberto Fernández usa el argumento de la autoridad con la misma finalidad, pero toma como autoridad a quien denomina "líder europeo", con el cual mantuvo una conversación: "Yo nunca olvido que un líder europeo me contó, cuando todo empezó en Europa, me dijo 'mirá, es un virus muy perverso, cuando te saca un metro de ventaja no lo alcanzás más” (13/08/2020), “es un virus que, como me dijeron aquella vez, nos saca un metro de ventaja y es muy difícil contenerlo” (29/09/2020).

$\mathrm{Al}$ mencionar lo que le dijo una vez sobre el virus un líder europeo en una conversación privada, el presidente argentino no solamente argumenta a favor de su política sanitaria sino también legitima su decir construyendo un ethos valorado de un presidente cercano a líderes internacionales.

\section{El argumento de la dirección}

En vínculo con el aumento de los índices de contagio, ocupación de camas en terapia intensiva y expansión del virus hacia toda la Argentina, se destaca el empleo del argumento de la dirección. Como explican Perelman y Olbrechts-Tyteca (1989), este argumento consiste en la advertencia de la existencia de una serie de etapas hacia un objeto determinado -temido, la mayoría de las veces- y la dificultad, si no la imposibilidad, de detenerse en el camino. ${ }^{9}$ En los discursos del presidente argentino se identifica una variante de este argumento que aquellos autores llaman argumento de la propagación. Se trata de ponerse en guardia contra ciertos fenómenos que tenderían a transmitirse progresivamente y convertirse, por este crecimiento, en nocivos. Si el fenómenos inicial ya es un mal, agregan, se apela a la noción de contagio, lo cual resulta del todo compatible con el COVID-19.

En los discursos del corpus, el presidente argentino usa el argumento de la propalación para persuadir al auditorio de que respete el ASPO: "La tasa de mortalidad nos está pasando un poco lo mismo, si suben los contagios es razonable pensar que la tasa de mortalidad también crezca" (31/07/2020), "pero el número de contagios crece, la atención crece en la demanda y los sistemas de salud empiezan a mostrar grados de ocupación preocupantes" (14/08/2020), "tenemos un problema muy serio que es se ha expandido en todo el territorio el virus" (14/08/2020), "ha empezado a teñirse, y que el norte de Santa Fe por la influencia de Chaco ha empezado a teñirse, y fíjense de Córdoba tiene una densidad de color más oscura porque tiene más casos (14/08/2020), "Santiago del Estero está lejos de eso, pero ha visto multiplicar, por la desaprensión de alguno, ha visto la cantidad de contagios de un modo muy peligroso (14/08/2020), "el problema se ha diseminado en todo el país" (14/08/2020), "los casos están en aumento" (28/08/2020), "siguen aumentando los casos" 
(28/08/2020), "el problema de diseminación del virus es enorme" (29/09/2020), "El dato este nos está hablando de provincias, que están alcanzando un nivel de estrés sanitario muy preocupante" (12/10/2020).

Como se puede observar en las citas, en las que se leen las palabras "preocupantes", "preocupante" y "estrés", el argumento de la dirección está ligado al pathos, en este caso la preocupación y el estrés de modo más explícito y el miedo de modo implícito ante el avance del COVID-19, que llevaría al auditorio a acatar el ASPO.

\section{La polémica}

La polémica, entendida como el enfrentamiento entre puntos de vista irreconciliables (Amossy, 2014) está más presente en los discursos aquí analizados que en los anteriores de Alberto Fernández sobre el COVID-19, lo que se vincula con las condiciones de producción ya comentadas. De esta manera, en las alocuciones de Alberto Fernández se destacan las negaciones metalingüísticas y polémicas (García Negroni, 1998; Maingueneau, 1987) que refutan enunciados afirmativos y puntos de vistas críticos hacia su gobierno, al acusarlo de que con el ASPO no respeta las libertades individuales y es autoritario: "no estamos discutiendo cuán libre somos, o cuán presos quedamos de la pandemia, estamos discutiendo del único modo que tenemos para combatir este problema" (31/07/2020), "Primero, nosotros un nunca restringimos libertades, solo cuidamos la salud de la gente (14/08/2020), "no es un acto de autoritarismo, ni un acto de prepotencia, entiendan que el riego de aumentar la circulación, de acercar los contactos físicos, es un problema" (14/08/2020).

Las críticas refutadas por Alberto Fernández son dirigidas desde sectores simpatizantes con CAMBIEMOS y del ex presidente Mauricio Macri. Esos mismos sectores, que no son identificados como contradestinatarios explícitos con algún colectivo de identificación (Verón, 1987), lo que atenúa la carga polémica, son refutados en los siguientes enunciados:

muchos hablaban de que Argentina no estaba preocupada por la vacuna, nos recomendaban seguir el ejemplo de otros, pero la realidad es que, en silencio, trabajando con México, trabajando con AstraZeneca, ese laboratorio, con el inmenso aporte de la Universidad de Oxford logramos ser junto con México los productores de la vacuna para toda América Latina y darle una solución a todo nuestro continente $(14 / 08 / 2020)$

Tenemos que estar muy orgullosos, y eso es cuando todos decían no se preocupan por la vacuna, nadie se está ocupando de la vacuna, por qué no miran a Oxford que es el que más se ha desarrollado, silenciosamente estábamos trabajando y solo lo anunciamos como pudimos anunciarlo (14/08/2020)

Alberto Fernández refuta en los enunciados citados a quienes acusan a su gestión de no avanzar en la provisión de vacunas para Argentina. Para ello, señala lo que se puede considerar un ejemplo en contario: el acuerdo de Argentina con AstraZeneca y México. 
Esos mismos sectores opositores, que cuestionaron el ASPO casi desde su inicio, son refutados también con las siguientes negaciones: "no es un enfermedad más, no es una gripe más" (31/07/2020), "el riesgo existe y no ha desaparecido" (14/08/2020).

En relación con esos enfrentamientos, Alberto Fernández sostiene: "Por favor, que no nos confundan, que no nos hagan discutir lo obvio, sigamos trabajando juntos, más unidos que nunca para poder pasar este mal tiempo del mejor modo" (13/08/2020).

Con estas palabras, el presidente argentino atenúa la polémica y construye un ethos moderado que resulta consistente con el ethos pedagógico oral.

\section{Las emociones}

Las alocuciones de Alberto Fernández incluyen enunciados de emoción formados por contenidos emocionales explícitos; se trata, en términos de Plantin $(2010,2014)$, de la emoción dicha.

En los discursos analizados es posible observar tres momentos. El primero está teñido de emociones disfóricas: "en esos lugares, lo que están temiendo es una segunda ola del virus" (06/08/2020), "lejos estoy de tranquilizarme con ese dato" (06/08/2020), "todo eso genera estrés, genera enojo, genera desánimo, y además la preocupación que genera la incertidumbre a la que la pandemia nos condena" (06/08/2020).

Como sostiene Amossy (2010), la repetición es un recurso para generar emoción, lo que se identifica en el enunciado anterior en el verbo "genera". Estas emociones disfóricas son consonantes con el argumento de la dirección comentado arriba, vinculado con el miedo, y tienden a legitimar la política sanitaria del gobierno, el ASPO, y a persuadir a la audiencia de que la respete.

En un segundo momento, hay protagonismo de emociones eufóricas y positivas, vinculadas con la noticia de que en Argentina se iba a fabricar la vacuna AstraZéneca / Universidad de Oxford, mediante un acuerdo de colaboración con el gobierno de México: "Para Latinoamérica los responsables de la cadena de producción serán Argentina y México; espero poder hablar en un ratito más con el Presidente José López Obrador, lo que para nosotros es una gran alegría" (12/08/2020), "Yo quiero expresar mi satisfacción por esto, porque pone a la Argentina en un lugar de tranquilidad" (12/08/2020), "con más esperanza" (14/08/2020), "que nos da la esperanza, la expectativa, de que en no mucho tiempo más vamos" (14/08/2020), "le dije que tenía una inmensa alegría de que la historia nos haya puesto juntos a producir la vacuna que resuelva el problema de América Latina, México y Argentina. Estoy feliz de esa unión que nos deparó la historia, y estoy feliz que también se haga en México el componente central de la vacuna" (14/08/2020), "mi alegría de hacerlo con México" (14/08/2020), "Quiero decirles una vez más que estoy muy contento de lo que hemos podido hacer con el laboratorio Astrazéneca, con la Universidad de Oxford, con México, que estoy muy contento" (14/08/2020), "estoy sinceramente orgulloso, porque todo esto es un proyecto sin fines de lucro" (14/08/2020), "me enorgullece" (14/08/2020). 
Alberto Fernández expresa también la emoción positiva de la tranquilidad en relación con el aumento de testeos: "Podemos tener cierta tranquilidad de que hemos aumentado la cantidad de testeos" (14/08/2020).

En muchos de estos enunciados, Fernández se construye como un actor que se autoatribuye emociones (Pantin, 2011,2014) como la alegría, la felicidad, la satisfacción, la tranquilidad, la esperanza y el orgullo. ${ }^{10}$ Estas emociones tienden a persuadir al auditorio sobre lo acertado de su política sanitaria, de modo de legitimar su liderazgo.

Empero, las emociones disfóricas siguen presentes en este segundo momento y orientan a que el auditorio siga acatando el ASPO, específicamente al generar preocupación y miedo. Esto sucede en un enunciado de emoción al mostrarse Alberto Fernández preocupado como el resto de los/las argentinos/as: "estamos en un momento donde todos estamos preocupados" (14/08/2020).

En la mayoría de los casos, sin embrago, los enunciados no contienen un término de emoción pero orientan en dirección de una emoción, en este caso la preocupación y el miedo: "el problema lo tenemos, está presente y en muchos lugares el riesgo aumentó, y los que hacemos aumentar el riesgo somos nosotros" (14/08/2020), "No estamos en condiciones de sentirnos con capacidad de disponer con quién me encuentro o no, sin que eso suponga un riesgo" (14/08/2020), "el riesgo siempre existe, el riesgo de que nosotros estemos tranquilos, nos relajemos, pensemos que esto ha pasado, eso es lo peor que nos puede pasar, porque el virus está" (14/08/2020), "la inmensa mayoría de argentinos que han entendido el riesgo" (14/08/2020), "el riesgo existe y no ha desaparecido" (14/08/2020), "el riesgo existe" (14/08/2020).

Como se manifiesta en las citas, se trata del recurrente empleo del lexema "riesgo" que el presidente argentino utiliza para representar los hechos a los que se refiere y que se vincula con el tópico de las consecuencias para generar una emoción (Plantin, 2010, 2013). En efecto, las consecuencias de algo riesgoso, es decir, peligroso, generan preocupación o miedo de modo estereotipado en nuestra cultura.

En un tercer momento, en los discursos presidenciales del 28/08/2020, el 29/09/2020 y del $12 / 10 / 2020$, las emociones son todas disfóricas. En algunos casos, aparecen enunciados de emoción dicha que incluyen al presidente como actor emocionado (Plantin, 2010, 201), en particular preocupado, sea a título individual o integrado a un "nosotros los de mi gobierno": "estamos muy preocupados" (28/09/2020), "nos preocupa Mendoza" (28/09/2020), "desde entonces estuve preocupado" (28/09/2020), "me preocupa” (28/09/2020) "tenemos una cantidad de contagios, en el Área Metropolitana, que nos preocupan" (28/09/2020), "nos preocupa" (12/10/2020).

Asimismo, Alberto Fernández expresa tristeza ante los datos económicos y el aumento de la pobreza: "Nosotros conocimos los datos del segundo trimestre de la economía y de la pobreza y obviamente nos han dejado muy entristecidos" (12/10/2020). El pathos contribuye así a construir un ethos sensible ante quienes más padecen a causa de las consecuencias económicas negativas de la pandemia COVID-19. 


\section{La puesta en escena mediática}

En la semiosis de la puesta en escena mediática se identifica un grupo de discursos en el que cumple la función de co-construir el ethos pedagógico oral analizado arriba en la dimensión verbal y tiende a que la audiencia acate la política sanitaria de Alberto Fernández y a que se consolide su liderazgo. Esto sucede en los discursos del 31/07/2020, 14/08/2020 y del 9/12/2020, que retoman la escenografía (Maingueneau, 2002) preponderante de las alocuciones previas de Alberto Fernández sobre el COVID-19 (Vitale, 2020).

En este sentido, en los discursos del 31/07/2020 y del 14/08/2020 se destaca que Fernández sea el único que dentro del espacio mediático se pare de donde está sentado y se acerque a una pizarra donde se proyectan gráficos de líneas, gráficos de tablas y mapas, recursos didácticos con información producida a partir de expertos:

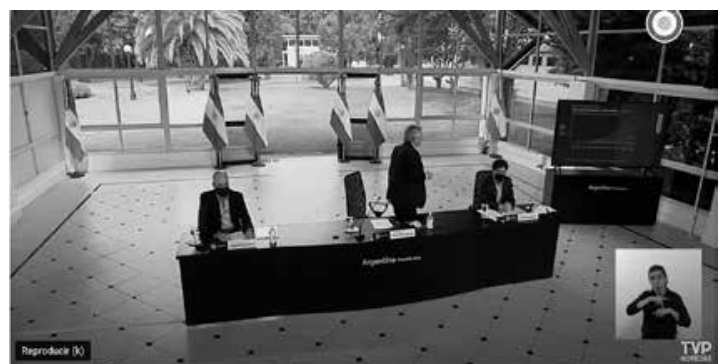

Figura 1. Discurso del 31/07/2020. Fuente: Sitio web de la Casa Rosada.

El presidente ocupa, así, un espacio solo a él permitido, lo que acrecienta su autoridad. Parado al lado de la pizarra explica y con su dedo índice orienta la mirada del espectador, evocando la escenografía (Maingueneau, 2002) del profesor:

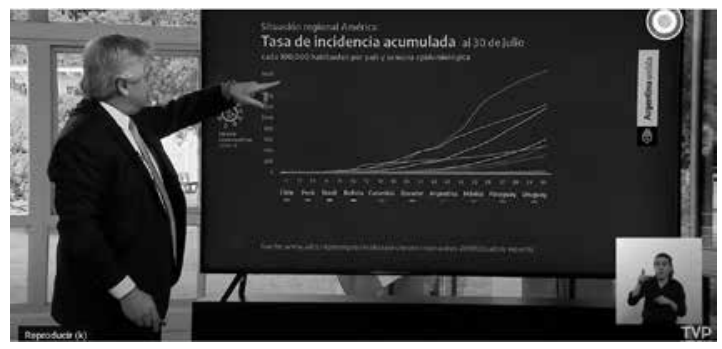

Figura 2. Discurso del 31/07/2020. Fuente: Sitio web de la Casa Rosada. 
En el discurso de 09/12/2020 Alberto Fernández se queda sentado y maneja el control remoto para que se sucedan diapositivas que ven directamente los espectadores mientras se escucha su voz en off.

En las diapositivas, predominan los números y los porcentajes, que Fernández va repitiendo y explicando en lo verbal. El protagonismo de las cifras genera un efecto de objetividad y recontextualiza (Bernstein, 2005) en el discurso político el saber experto de los epidemiólogos y especialistas en estadísticas.

A medida que se suceden las diapositivas, Fernández va interpelando de modo recurrente a los espectadores, con el imperativo, mediante los verbos "mirar", "ver" y "fijarse", que acrecientan el contacto y orientan también, como su dedo índice, la mirada de la audiencia y lo posicionan en un lugar de poder: "miremos" (31/07/2020, 14/07/2020), "miren" (31/07/2020, 14/08/2020, 12/10/2020), "fíjense" (31/07/2020, 14/08/2020), 09/10/2020), "vean" (14/08/2020).

La ubicación del cuerpo de Alberto Fernández en el espacio, en particular entre quiénes se sienta o sitúa a su lado, y las características del espacio donde produce sus alocuciones están semiotizadas. En efecto, en los discursos del 31/07/2020 y del 14/08/2020 está sentado entre el Jefe de la Ciudad de Buenos Aires, Horacio Rodríguez Larreta, de la oposición, y el gobernador de la Provincia de Buenos Aires, Axel Kicillof, aliado político. Esto tiende a generar el sentido de unión nacional, muy marcado en sus discursos anteriores sobre el COVID-19 (Vitale, 2020).

En la conferencia de prensa que Alberto Fernández dictó el 12/08/2020 para anunciar la producción argentina junto con México de la vacuna AstraZéneca / Universidad de Oxford, está sentado en el medio del Ministro de Salud, Ginés González García, y la Secretaria de Acceso a la Salud, Carla Vizzotti. La escena focaliza así la connotación de salud pública.

La pared de fondo de esta conferencia de prensa y del discurso del 09/10/2020 es de color celeste con escritos en letras blancas, colores de la bandera argentina. Dice "Argentina unida", lo que lleva a leer los colores patrios como signo de unidad. Por otra parte, hay banderas argentinas detrás de Alberto Fernández en los discursos del 31/07/2020, del 14/08/2020 y $28 / 09 / 2020$.

El fondo vidriado que permite ver el exterior del jardín de la quinta presidencial de Olivos presente en los discursos del 31/07/2020 y del 14/08/2020, como sucedió en las alocuciones presidenciales previas sobre el COVID-19, connotan la transparencia y la verdad a la vez que establece una intericonicidad (Courtine, 2011) con la puesta en escena del discurso político de Mauricio Macri y genera así el sentido de unidad (Vitale, 2020).

El discurso del 28/08/2020, que anuncia la autorización de reuniones hasta diez personas en espacios abiertos, presenta la particularidad de que Alberto Fernández está en una habitación pequeña de la residencia presidencial de Olivos, que nunca se mostró en su comunicación política anterior ni aparecerá en la posterior. Además, se trata de un mensaje grabado, no en vivo, como todos los demás: ${ }^{11}$ 


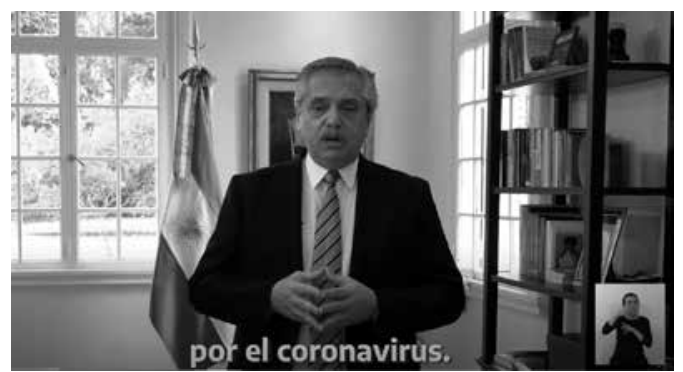

Figura 3. Discurso del 28/08/2020. Fuente: Sitio web de la Casa Rosada.

Este mensaje del 28/08/2020 ubica a Fernández en un espacio pequeño, íntimo, de modo que se crea otra escenografía en la que él no habla tanto como un profesor sino como un ser más próximo. El encuadre deja ver una biblioteca a la derecha y a la izquierda una ventana, que permite ver el verde del jardín, por donde entra la luz, con connotación de transparencia. La escena connota una cercanía con el presidente, quien con su voz en off comenta algunas diapositivas, que ocupan todo el cuadro, con gráficos de líneas, de barras y de mapas pero también los espectadores pueden observar otras escenas de la vida del presidente, como teleconferencias en las que participó. Estas imágenes de Alberto Fernández se combinan con imágenes, por ejemplo, de trabajadores de la salud, connotando que el presidente trabaja codo a codo con ellos por el bienestar de los/las argentinos/as. ${ }^{12}$ Importa, también, que una de esas imágenes es una gran bandera argentina, flameando, lo cual connota la unión nacional.

En cuanto a su discurso del 24/09/2020, presenta la particularidad de que no lo pronuncia en CABA, lugar donde se desarrollaron todas sus alocuciones sobre el COVID-19, sino en la ciudad de Rosario, en la provincia de Santa Fe. Esto es entendible por dos motivos: por un lado, se trata del lanzamiento del Plan DetectAR federal y, por otra parte, esta ciudad y esta provincia estaban siendo muy afectadas por el COVID-19.

La puesta en escena mediática de este discurso difiere de las otras porque se trata de un espacio abierto, en el que hay un escenario, frente al que en sillas como si fuesen butacas, espaciadas, se ubican, cual público que mira un espectáculo, el intendente de la ciudad de Santa Fe, autoridades provinciales y municipales, integrantes de los medios de comunicación e invitados especiales.

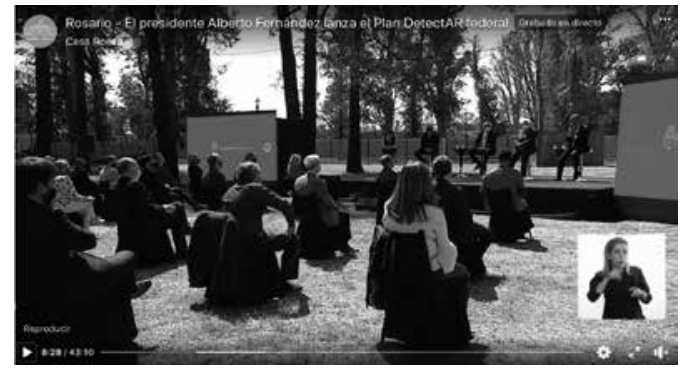

Figura 4. Discurso del 24/08/2020. Fuente: Sitio web de la Casa Rosada. 
En el escenario, está Alberto Fernández sentado en el medio entre, a su izquierda, el Ministro de Salud, Ginés González García y el intendente de Rosario, Pablo Javkin, y, a su derecha, el gobernador de la provincia de Santa Fe, Omar Perotti y la vicegobernadora, Alejandra Rodenas. Además, la transmisión se inicia con la voz en off de una locutora que aclara quiénes son los miembros del público y se refiere a la escena de enunciación como a "este acto". El acto en Rosario con la presencia de su intendente, de una fuerza política diferente (de pasado radical y del ARI, asumió al frente de un partido nuevo, CREO) a la del presidente, junto con el gobernador peronista del mismo espacio político que Fernández connotan la unidad ante la lucha contra el COVID-19.

En este caso, se pueden observar en los extremos del escenario dos pantallas digitales, que son las que aparecen normalmente al inicio de la transmisión de las conferencias de prensa o anuncios oficiales del presidente, de color celeste, con letras blancas que dicen el slogan "Argentina unida". Reaparece así la idea de unidad que es un leitmotiv en la discursividad de Fernández sobre la pandemia, a la vez que las pantallas, que no son usadas, constituyen un lazo semiótico con esos otros mensajes públicos.

La puesta en escena mediática con auditorio a quien habla y mira el presidente, que lleva a participar al espectador mediante la identificación con ese auditorio, fue característica de la comunicación política de Cristina Fernández de Kirchner tal como analizaron Cingolani y Fernández (2019) y es así evocada como intericonicidad (Courtine, 2011).

En el anuncio oficial del 9/10/2020, por último, Alberto Fernández está sentado entre el gobernador de Jujuy, Gerardo Morales, de la oposición, y el gobernador de Santa Fe, Omar Perotti, aliado político, y el gobernador de Neuquén Omar Gutiérrez, de otra fuerza política, el Movimiento Popular Neuquino. Esta ubicación del cuerpo de Fernández en el espacio, entre quiénes se sienta, connota la idea de unidad a la vez que se relaciona con la expansión del COVID-19 en toda la Argentina. Un detalle, empero, es importante, por primera vez un símbolo del peronismo aparece con claridad en la comunicación política de Alberto Fernández: se trata de la fotografía de Eva Perón.

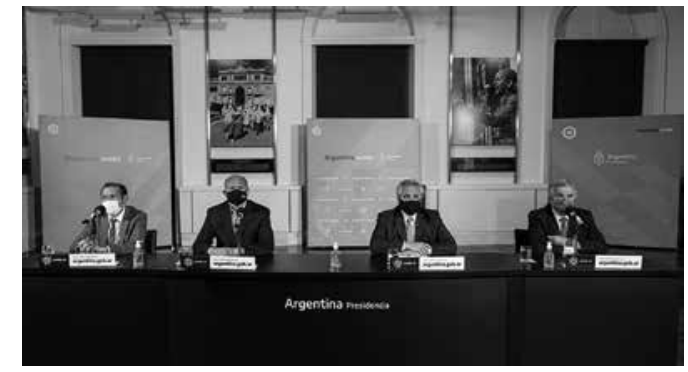

Figura 5. Discurso del 12/10/2020. Fuente: Sitio web de la Casa Rosada. 


\section{Conclusiones}

Del análisis realizado de los discursos que Alberto Fernández pronunció con motivo del COVID-19 entre el 31/07/2020 y 12 /10/2020 se desprende que se mantiene el ethos pedagógico oral que se configuró de modo muy marcado en todas sus alocuciones previas sobre la pandemia. De esta manera, se ratifica su ethos previo, lo que tiende a otorgarle autoridad y legitimidad para implementar su política sanitaria centrada en el ASPO.

Frente a un panorama más complicado respecto del COVID-19 a nivel nacional en comparación al existente en su discursividad anterior, Fernández despliega una argumentación basada en la analogía mediante la cual se posiciona en el lugar de un médico que le dice la verdad a sus pacientes, la audiencia, a quienes busca persuadir de que el único remedio es el ASPO. Asimismo, la analogía sirve para refutar puntos de vista críticos hacia su gestión sanitaria que lo acusan de autoritario y de coartar las libertades. El argumento de autoridad ratifica la valoración del saber médico y el argumento de la dirección tiende a generar miedo en el auditorio para que acate el ASPO.

En este sentido, se destaca que, en los discursos aquí analizados, a diferencia de las alocuciones anteriores de Fernández sobre el COVID-19, el pathos adquiere mayor importancia, lo mismo que la dimensión polémica ante contradestinatarios vinculados con simpatizantes de Mauricio Macri, de quienes recibe las acusaciones nombradas. Sin embargo, el presidente no identifica de modo explícito el blanco polémico y suele reducir las refutaciones a contraaserciones, de manera que su ethos es moderado y no agresivo. A esto mismo contribuye el ethos pedagógico oral, puesto que el educador, dije, se aleja de la polémica. Las emociones expresadas, por otra parte, dan de sí una imagen de gobernante que se compadece de los más pobres. ${ }^{13}$

La puesta en escena mediática resulta menos homogénea que la de las alocuciones previas al 31/07/2020, lo que se vincula con la expansión del virus por toda la Argentina y a la mencionada tensión que surgió con el Jefe de la Ciudad de Buenos Aires. Por un lado, esa puesta en escena co-construye el ethos pedagógico oral, que dota a Fernández de autoridad y tiende a generar el sentido de unidad nacional, necesaria para la correcta implementación de una política sanitaria. La ubicación del cuerpo presidencial, entre quiénes se sienta, y el hecho de que no hegemonice la palabra pública, sino que la comparta con oradores que no solamente son de su espacio político sino también de la oposición, contribuyen a generar el ethos moderado y ese sentido de unidad nacional.

Resulta así importante que como otro indicio de búsqueda de unidad se mantenga respecto de sus alocuciones previas el uso de metacolectivos asociados a los paradestinatarios (Verón, 1987), a quienes en el discurso político va dirigida la argumentación: "argentinos", "argentinos" y "gente". Sobre "la gente", Verón (1999:117) advirtió que indica una pérdida de la percepción de las identidades sectoriales de la sociedad. La palabra "pueblo", en cambio, que habilita disputas por establecer quién es el pueblo y señalar el límite contra un poder hegemónico (Laclau 2005), es usado en una única oportunidad en cuanto colectivo (14/08/2020), referido al pueblo de la Provincia de Buenos Aires.

La puesta en escena mediática sobre el COVID-19, por otra parte, establece una relación de intericonicidad con la comunicación política de Cambiemos: vidrios transparentes que dejan ver los jardines de la quinta presidencial de Olivos y espacios abiertos donde el verde 
de la naturaleza es protagonista. Al mismo tiempo, también hay en el discurso pronunciado en Rosario una intericonicidad con las cadenas nacionales de Cristina Fernández de Kirchner en las que había público presente y los espectadores entran a la escena mediante la identificación con ese público (Cingolani y Fernández, 2019).

Esto se vincula con el régimen de la mirada preponderante: entre el 15 de marzo y el 17 julio de 2020, en las conferencias de prensa ante los periodistas y la presencia de estos en varios de los anuncios oficiales, Alberto Fernández empleó de modo casi predominante el régimen enunciativo de la mirada que Verón (1983) llama la figuración escénica (Vitale, 2020). Entre los discursos pronunciados entre el 31 de julio y el 2 de octubre de 2020 hubo una sola conferencia de prensa y, salvo en el discurso de la ciudad de Rosario, no hubo público presente. El régimen enunciativo de la mirada protagonista fue, entonces, la mirada a la cámara y el contacto directo con el espectador (Verón, 1983).

Por último, restará indagar si estas continuidades y discontinuidades en la retórica presidencial de Alberto Fernández ante el COVID-19 responden sólo a mutaciones en las condiciones de producción de sus discursos o dan cuenta también de un liderazgo político en construcción que está (re)definiendo sus lineamientos comunicativos. En efecto, si se asume que el discurso, en sus diversas materialidades significantes, no es expresión de una identidad previa sino que de modo performativo la construye (Anderson, 2007) y se acepta que la puesta en escena mediática constituye la faz comunicativa de una acción política (Cingolani y Fernández, 2010), esa tarea será del todo relevante.

\section{Notas}

1. Se trata de la conferencia de prensa del $31 / 08 / 2020$ y de los discursos y anuncios oficiales del 12/08/2020, 14/08/2020, 18/09/2020, 29/09/2020 y del 12/10/2020. Tomé como fuente de estos discursos, incluidos los videos, los disponibles en el sitio web de la Casa Rosada: https://www.casarosada.gob.ar/ De allí provienen todas las citas. No incluyo el mensaje del gobierno sobre el COVID-19 del 28/08/2020 porque el enunciador no es Alberto Fernández sino una locutora cuya voz está en off.

2. Otras ocurrencias son: “¿qué nos está pasando? Nos está pasando que como estamos mirando números y números, empezamos a normalizar los números” (03/08/2020), “Cómo se explica esto? Bueno, esta es la conformación del país que nos dimos, un país que concentra mucho en el puerto de Buenos Aires ..." (03/08/2020), “¿saben qué pasa? No podemos hacerlo, no podemos hacerlo" ( 03/08/2020), "Ahora, ¿qué es lo que nos está pasando? (...).el 65 por ciento de los casos hoy ocurren en el Interior del país y el AMBA quedó reducido alrededor del 35 por ciento" (29/08/2020), “¿Estamos bien? No, no estamos bien" (12/10/2020).

3. Otros ejemplos: "esta curva, esto es la cantidad de personas que han fallecido, contagiadas que han fallecido" (03/08/2020), "En el mes de mayo la cantidad de muertos eran 375 , en junio fue 700 la cantidad de personas fallecidas (...). Eso quiere decir que cada veinticuatro días, hasta aquí, hemos duplicado la cantidad de fallecimientos (03/08/2020), 
"la tasa de incidencia acumulada al 12 de agosto, esto quiere decir cada cien mil habitantes cuánta gente se contagia" (13/08/2020).

4. Otras ocurrencias son: "recuerden que acá lo que se calcula es cuánto contagiados tenemos cada cien mil habitantes" (06/08/2020), "Ya les dije al comienzo que mi dilema ético lo resolvía el primer día" (13/08/2020), "aquel 19 de marzo, en que por primera vez tuve que hablarles y explicarles sobre cómo hemos evolucionado con el tema de la pandemia" $(19 / 10 / 2020)$ "Yo los invito a que repasemos juntos esos datos, porque me van a permitir explicar en qué situación estamos" (12/10/2020) y "yo les comentaba al comienzo" $(12 / 10 / 2020)$.

5. Otros casos, ente otros, que se pueden idenitifcar son: "el total del país tenemos 55 por ciento de cama ocupadas, y 45 por ciento de camas disponibles" (03/08/2020), "Ciudad Autónoma de Buenos Aires hoy ocupa el 75 por ciento de las camas, AMBA el 68 por ciento, GBA el 64 por ciento, el total del país es casi del 60 por ciento, 58 por ciento (14/08/2020), "Si nosotros miramos lo que pasaba hace dos meses atrás, el 95 por ciento, 93 por ciento, de los contagios ocurrían en el AMBA" (29/09/2020), "el 65 por ciento casi de los contagios devienen de las provincias y sólo el 35 por ciento de los contagios devienen del Área Metropolitana de Buenos Aires" (29/09/2020), "qué porcentaje de infectados ha fallecido como consecuencia del coronavirus ronda 2,7 " (12/10/2020), "el 65 por ciento casi de los contagios devienen de las provincias y sólo el 35 por ciento de los contagios devienen del Área Metropolitana de Buenos Aires".

6. Ver, por ejemplo, "La imagen de Alberto Fernández cayó por sexto mes", Clarín, 06/07/2020; "Casi el $60 \%$ de la sociedad pide flexibilizar la cuarentena y está más preocupada por su situación económica que por el coronavirus", Infobae, 11/08/2020, "Se desplomó la imagen positiva de Alberto Fernández a niveles previos a la asunción", Perfil, 03/09/2020, "Encuesta; por primera vez en toda la. cuarentena, la imagen de Alberto Fernández dio negativa”, Perfil, (09/10/2020). Página 12, por su parte, denunció una campaña mediática de desprestigio al presidente en torno a la medición de su imagen pública, a la vez que publicó datos de una encuesta que muestran que la imagen positiva en 2020, si bien alta, había ido bajando desde abril a noviembre, "A pesar de la pandemia y la crisis Alberto Fernández mantiene alta la imagen positiva", 07/12/2020.

7. Ver "Alberto Fernández ya firmó el decreto simple que le quita a la Ciudad de Buenos Aires 30 mil millones de pesos anuales de Coparticipacón”, Infobae, 09/09/2020.

8. 8. Perelman y Olbrechs Tyteca (1989: 569-601) conciben la analogía como un tipo de argumento que plantea una similitud de estructuras, cuya fórmula más general es $\mathrm{A}$ es a $\mathrm{B}$ como C es a D. A y B son los elementos del tema, que contiene la conclusión, y C y D son los elementos del foro, que sirven para sostener el razonamiento.

9. Destaco que Perelman y Olbrechts-Tyteca (1989) vinculan el argumento de la dirección con el miedo.

10. Fernández sigue así preceptos de la retórica clásica, en cuanto a que el orador, para despertar emociones en el auditorio, debe estar él mismo emocionado (Cicerón De orat. 2,45,189; Quintiliano Inst. 6,2,3).

11. La excepción es el mensaje grabado con voz femenina en off del 18/09/2020 que, aclaré, no incluyo en el corpus aquí analizado porque el enunciador no es Alberto Fernández. 
12. El cierre del discurso "Los abrazo a la distancia con el cariño y el afecto de siempre" tiende a ratificar esa misma cercanía.

13. Esta característica es compartida con el ethos de Cristina Fernández de Kirchner. Por otra parte, en Vitale (2020) expliqué que el ethos pedagógico oral conecta de modo semejante la imagen pública de Alberto Fernández con los discursos presidenciales de la ex mandataria, que configuraron una escenografía que califiqué de "profesoral"; el ethos más moderado del actual presidente, en cambio, lo diferencia del ethos presidencial de ella, de mayor carga polémica.

\section{Bibliografía}

Amossy, R. (2014). Apologie de la polémique. Paris: Presses Universitaires de France.

Anderson, D. (2007) Identity's Strategy: Rhetorical Selves in Conversion. Columbia: University of South Carolina Press.

Barthes, R. (1992). Retórica de la imagen, en Lo obvio y lo obtuso. Barcelona: Paidós.

Bernstein, B. (2005). Clases, códigos y control II. Hacia una teoría de las transmisiones educativas. Madrid: Akal.

Cicerón, M. T. (2002). Sobre el orador, trad., int. y not. de J. J. Iso, Madrid.

Cingolani, G. y M. Fernández (2019). Cristina, un espectáculo político. Cuerpos, colectivos y relatos en la última presidencia televisiva. Buenos Aires: Prometeo.

Cingolani, G. y M. Fernández (2010). Televisión y política: espacio público, puestas en escena y regímenes de visibilidad, Oficios Terrestres 25, 37-49.

Courtine, J-J. (2011). Discurso e imagens: para uma arqueologia do imaginário, en Sargentini, V.; L. Curcino y C. Piovezani (orgs.). Discurso, Semiologia e História. São Carlos: Claraluz, 145-162.

Fabbri Jr, F. y F. Ormaneze (2020). O discurso nos limites da obediência: enunciados que afagam ou abafam conflitos entre Mandetta e Bolsonaro na crise do coronavírus, Cadernos de Campo:Revista de Ciências Sociais, 28, 175-191.

Fausto Neto, A. (2020). Trajetórias discursivas em torno do coronavírus, DeSignis, 33, 245-257.

García Negroni, M. M. (1998). La negación metalingüística: argumentación y escolaridad, en Signo y Seña, 9, 227-252.

Han, L. (2020). Reading Chinese anti-COVID-19 pandemic narratives on facemasks as the art of disaster governance: a semiotic and biopolitical survey, Social Semiotics, 1-7.

Karam Cárdenas, T. (2020). Funciones comunicativas y altibajos discursivos de la autoridad sanitaria en México ante la pandemia de la COVID-19. Sintaxis, 15-34.

Lebaud, D. (2020). De Liberté, Égalité, Fraternité aux mots pour dire la pandémie de la Covid-19, Inter Faculty, 10, 203-221.

Laclau, E. (2005). La razón populista. Buenos Aires: FCE.

Maingueneau, D. (1987). Nouvelles Tendances en Analyse du Discours. Paris: Hachette. . (2002). Problèmes d'ethos, Pratiques, 113/114, 55-67.

. (2014). Discours et analyse du discours. Paris: Armand Colin. 
MIRCo (2020). Pandemic discourses and the prefiguration of the future, Language, Culture and Society 2 (2), 227-241.

Molina, T. (2003). Características del discurso oral pedagógico, Lengua y habla 8, 80-96.

Perelman, Ch. y L. Olbrechts-Tyteca (1989) Tratado de la argumentación. La nueva Retórica. Madrid: Gredos.

(1977). Lempire rhétorique. Rhétorique et argumentation. Paris: Librairie Philosophique J. Vrin.

Plantin, Ch. (2011). Les bonnes raisons des émotions. Principes et méthode pour le étude du discours émotionné. Berna: Peter Lang.

. (2010). As razões das emoções, en E. Mendes e I. L. Machado (Orgs.) As emocioes no discurso. vol II. Campinas: Mercado de Letras, 57-79.

Quintiliano, M. F. (1944). Instituciones oratorias, trad. y not. I. Rodríguez y P. Sandier, Buenos Aires.

Slimovich, A. (2021). Pandemia global y política mediatizada. La comunicación presidencial argentina y sus repercusiones en Twitter en el primer semestre 2020, Comunicación y hombre 17, pp. 85-102.

Vasilachis de Gialdino, I., coord. (2006). Estrategias de investigación cualitativa. Barcelona: Gedisa.

Verón, E. (1983). Il est là, je le vois, il me parle, Communications 38, 98- 120.

. (1987). La palabra adversativa. Observaciones sobre la enunciación política, en

AA.VV. El discurso político. Lenguajes y Acontecimientos. Buenos Aires: Edicial, 13-26.

. (1999). Efectos de agenda. Barcelona: Gedisa.

(2001). El cuerpo de las imágenes. Buenos Aires: Norma.

Vitale, M. A. (2020). Discurso presidencial sobre el COVID-19. El caso de Alberto Fernández en Argentina, deSignis 33, 113-125.

Zamudio, B. y A. Atorresi (2000). La explicación. Buenos Aires: EUDEBA.

\begin{abstract}
In a previous paper (Vitale, 2020), I analyzed the construction of a pedagogical oral ethos in the monological Alberto Fernández's speeches about the COVID-19 pandemic, from 15th March to 17th July. In this article I will focus on his speeches from 31st July to 12th October. I describe how this ethos is maintained and I characterize the greater presence of argumentative techniques (Perelman y Olbrechts-Tyteca, 1989), polemic dimension (Amossy, 2014) and pathos (Plantin, 2010, 2011) compared to the first stage of his political pandemic communication. I will consider, as well, the mediatic staging (Cingolani y Fernández, 2010, 2019; Verón, 2001). I will describe the reformulations in communication, marked by the increase in case numbers and deaths by COVID-19 and the growing confrontation with opposing politicians.
\end{abstract}

Keywords: argumentation - COVID-19 - polemic - emotions - media staging. 
Resumo: Em trabalho anterior (Vitale, 2020), analisei a construção da imagem de si ou ethos pedagógico oral no discurso monologal do presidente argentino Alberto Fernández relativo à pandemia de COVID-19 nas coletivas de imprensa e comunicados oficiais que proferiu entre 15 de março e 17 de julho de 2020. Neste artigo, concentro-me em seus discursos produzidos entre 31 de julho de 2020 e 12 de outubro de 2020, para observar como esse ethos é mantido, caracterizando aí a maior presença de técnicas argumentativas (Perelman e Olbrechts-Tyteca, 1989), a dimensão polêmica (Amossy, 2014) e o pathos (Plantin, 2010, 2011) na primeira etapa de sua comunicação política sobre a pandemia. Considero também a encenação midiática (Cingolani e Fernández, 2010, 2019; Verón, 2001) para descrever as reformulações dessa comunicação, marcada nesta segunda etapa pelo aumento de contágios e mortes por COVID-19, a disseminação do vírus em toda a Argentina e o aumento do confronto entre o governo nacional e a oposição, incluindo o chefe de governo da Cidade de Buenos Aires.

Palavras-chave: argumentação - COVID-19 - polémica - emoções - cena de mídia.

[Las traducciones de los abstracts fueron supervisadas por el autor de cada artículo] 